\title{
Prevalence of Risk factors for Coronary heart disease among the workers of an industry of South India
}

Dinesh Peraje Vasu ${ }^{1}$, Annarao Gunderao Kulkarni ${ }^{2}$, Namratha Kurunji Gangadhar ${ }^{3}$

${ }^{1}$ Associate Professor, Department of Community Medicine, KVG Medical College and Hospital, Sullia (D.K), Karnataka-574327; ${ }^{2}$ Professor, Department of Community Medicine, East Point College of Medical Sciences, Bengaluru, Karnataka - 560049; ${ }^{3}$ Associate Professor, Department of Microbiology, KVG Medical College and Hospital, Sullia (D.K), Karnataka - 574327

\begin{tabular}{|c|c|c|c|c|c|c|c|c|}
\hline Abstract & Introduction & Methodology & Results & Conclusion & References & Citation & \multicolumn{2}{|c|}{ Tables / Figures } \\
\hline \multicolumn{9}{|c|}{ Corresponding Author } \\
\hline \multicolumn{8}{|c|}{$\begin{array}{l}\text { Dr Dinesh P V, Associate Professor, Department of Community Medicine, KVG Medical College and } \\
\text { Hospital, Sullia (D.K.), Karnataka - } 574327 \\
\text { E Mail ID: sullia.dinesh@gmail.com }\end{array}$} & 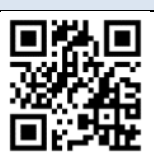 \\
\hline
\end{tabular}

\section{Citation}

Vasu DP, Kulkarni AG, Gangadhar NK. Prevalence of Risk factors for Coronary heart disease among the workers of an industry of South India. Indian J Comm Health. 2020;32(4):637-642. https://doi.org/10.47203/IJCH.2020.v32i04.005

Source of Funding: Nil Conflict of Interest: None declared

\section{Article Cycle}

Received: 15/06/2020; Revision: 05/07/2020; Accepted:21/07/2020; Published:31/12/2020

This work is licensed under a Creative Commons Attribution 4.0 International License.

\section{Abstract}

Introduction: Industrial workers are a captive group and can be considered ideal for increasing awareness, adopting preventive strategies and thus to the control of cardiovascular diseases. However, there are limited numbers of studies which are carried out to estimate the coronary heart disease risk burden in factory settings of India. Objectives: To estimate the prevalence of coronary heart disease risk factors among the workers of a nylon yarn manufacturing factory in South India. Methods: A cross sectional study was conducted among all employees aged 20 -59 years employing a clinical examination and biochemical estimation. Body Mass Index, Blood Pressure, Fasting Blood sugar and Lipid profile were measured. Patients known to have coronary heart disease, those aged less than 20 years and those aged more than 59 years were excluded. Results: 320 workers were evaluated. Their mean age was 32 years. Among the study population, $6.25 \%$ were obese and $21.8 \%$ were current smokers. $14.7 \%$ of them were found to be hypertensives and $61.87 \%$ were pre-hypertensives. $5.9 \%$ of the workers were diabetic and $14.6 \%$ had impaired fasting glucose. $55.93 \%$ of them had an increased Total cholesterol / High Density Lipoprotein ratio. Conclusion: This study demonstrates a high prevalence of risk factors for coronary heart disease among a comparatively young population in a South Indian industrial setting.

\section{Keywords}

Prevalence; Risk factors; Cardiovascular Diseases

\section{Introduction}

Non communicable diseases (NCDs) account for more than 36 million deaths each year globally, (1) striking hardest at the world's low- and middleincome populations. (2) Among these deaths, cardiovascular diseases (CVDs) contribute the most (17.3 million/year or 48\%).(3)
Cardiovascular diseases (CVDs) account for $24 \%$ of all deaths (4) in India which is $17 \%$ of the global CVD mortality. (5)

Among the CVDs, coronary heart disease (CHD) is the leading cause of death worldwide. (6) More than $60 \%$ of the global burden of coronary heart disease occurs in developing countries. India tops the list of countries with highest number of deaths followed by 
China and Russia. While genetic factors play a part, $80-90 \%$ of people dying have one or more major risk factors (7) which are influenced by life style.

Industrialization promotes urbanization and migration. With urbanization and migration, there is increase in the levels of potentially reversible CVD risk factors (7). All these factors hold good for industrial workers when they migrate to urban areas for job opportunities. The knowledge of risk factors in this selective group can be used in the future for increasing the awareness and initiating preventive activities in them, thus reducing the cardiovascular morbidity.

\section{Aims \& Objectives}

To estimate the prevalence of risk factors for coronary heart disease among industrial workers employed in a nylon manufacturing industry.

\section{Material \& Methods}

Study Type: Cross sectional study

Study Population: Employees of the textile division of a nylon yarn producing industry

Study Area: Nylon Yarn manufacturing industry in Chennai

Study Duration: April to June 2015

Sample size: All employees satisfying the inclusion and exclusion criteria. Thus 320 employees were included out of 393 employees.

Inclusion criteria: Those workers between 20-59 years of age were included for the study

Exclusion criteria: Those not willing to participate in the study

Methodology: The author and medical officer recruited by the industry presented the pretested questionnaire to all participants which contained basic details of participants like name, employee number, age, sex and also on history of any CHD/ stroke or medications for any long-term illness.

All physical parameters were then measured in the medical unit of the industry which included blood pressure, height and weight.

Blood pressure was measured in the right arm after a rest of five minutes in the sitting position. The systolic and diastolic pressures were measured twice over a period of five minutes and average of the two measurements was used for analysis. (8)

Height was measured in centimeters using a stadiometer which was caliberated to the nearest $0.5 \mathrm{~cm}$
Weight was measured using a bathroom scale (9) which was validated on a daily basis with known weights.

Participants were then sent to the laboratory for blood investigations which included fasting blood sugar and fasting lipid profile. Before sending the participants for investigation, they were clearly explained the necessity of 12 hours of overnight fasting before blood examination. (10) In the laboratory, glucose was analysed by Glucose oxidase method, cholesterol by CHOD method and triglycerides by GPOD method.

Working Definition $(9,11,12,13,14,15)$

Pre-hypertension: Systolic BP of 120-139 mmHg or diastolic BP of $80-89 \mathrm{mmHg}$ in non-hypertensive subjects

Stage 1Hypertension: Systolic blood pressure (BP) $>139 \mathrm{mmHg}$ and $<160 \mathrm{mmHg}$ or diastolic BP $>89$ $\mathrm{mmHg}$ and $<100 \mathrm{mmHg}$.

Stage 2 Hypertension: Systolic blood pressure (BP) $\geq 160 \mathrm{mmHg}$ or diastolic BP $\geq 100 \mathrm{mmHg}$.

Normal Blood Pressure: Systolic Blood Pressure $<120 \mathrm{mmHg}$ and Diastolic Blood Pressure $<80 \mathrm{mmHg}$. Diabetes: Fasting blood glucose $\geq 126 \mathrm{mg} / \mathrm{dl}$ or 2 hour post-load blood glucose $\geq 200 \mathrm{mg} / \mathrm{dl}$ or history of treatment for diabetes

Impaired fasting glucose: Fasting blood glucose $\geq 100$ $\mathrm{mg} / \mathrm{dl}$ and $<126 \mathrm{mg} / \mathrm{dl}$, in the non-diabetic population.

Tobacco use: Consumption of any form of tobacco in the past 6 months and continuing to use them. The types of tobacco consumption considered included smoked (cigarettes, beedis and cigars), oral (tobacco chewed, pan masala, etc.) and inhaled forms (snuff). Hypercholesterolaemia: Total blood cholesterol levels $\geq 200 \mathrm{mg} / \mathrm{dl}$

Hypertriglyceridaemia: Fasting serum triglyceride levels $\geq 150 \mathrm{mg} / \mathrm{dl}$

Decreased high density lipoprotein cholesterol: Fasting blood HDL-cholesterol $<40 \mathrm{mg} / \mathrm{dl}$

Increased Low density lipoprotein cholesterol: Fasting Blood LDL- cholesterol $>129 \mathrm{mg} / \mathrm{dl}$

Adverse total cholesterol/high density lipoprotein cholesterol ratio: $\geq 4.5$

Overweight: Body mass index $\geq 25 \mathrm{~kg} / \mathrm{m} 2$

Ethical Approval: Obtained from Institutional Ethics Committee.

Consent: Approval for conducting the study was obtained from both management and employee representatives. Informed consent form was obtained from all the participants. 
Data Analysis: Data entry and statistical analysis were performed using Microsoft Excel 2007 and SPSS version 9 software. Only frequency and percentages were included in analysis as this is only a descriptive study.

\section{Results}

Out of the 320 eligible workers, $90.62 \%$ were males and $9.37 \%$ were females. (Table 1) The mean age of the participants was 32 years and nearly $68 \%$ of the participants were in 20-29 years age group. The mean values of various clinical, laboratory and anthropometric measurements are seen in (Table 2). The overall prevalence of various risk factors are as follows: Prehypertension (61.89\%), Hypertension (14.70\%), Diabetes mellitus (5.9\%), Impaired Fasting Glucose (14.6\%), Hypercholesterolemia (12.5\%), Hypertryglyceridemia (16.25\%), Total Cholesterol/HDL ratio More than 4.5 (54.06\%), Current tobacco smokers (21.87\%), Preobese $(31.56 \%)$, Obese $(6.25 \%)$ and those with increased waist hip ratio (11.87\%). (Table 3 )

However, as per the WHO recommendations for defining health risks associated with BMI in Asians, $51(15.94 \%)$ were in the high to very high risk (BMI $\geq 27.5 \mathrm{Kg} / \mathrm{m} 2)$ and $127(39.68 \%)$ in the moderate to high risk (BMI $\geq 23 \mathrm{Kg} / \mathrm{m} 2$ but less than $27.5 \mathrm{Kg} / \mathrm{m} 2$ ). While $61.56 \%$ of the surveyed population had atleast one risk factor, $20 \%$ and $1.87 \%$ had atleast two or three co existing risk factors for coronary heart disease respectively. (Table 4)

\section{Discussion}

This study was done among a comparatively young Indian population which revealed that the prevalence of risk factors among them were high. Even in $20-29$ years age group people, only $11.87 \%$ and $49.06 \%$ were normotensive and euglycemic respectively.

The proportion of workers with hypertension was $14 \%$ in the present study which is lesser than that of the study done by Pyakurel et al (16) and Sekhri et al (17) which reported $33.6 \%$ and $21 \%$ to be hypertensives. However, the diabetics were slightly higher in the present study when compared to that of Pyakurel et al (5.9\% Vs $4.2 \%)$. The proportion of diabetics was $16 \%$ in the study done by Sekhri et al (17). The present study also revealed that $84.68 \%$ had dyslipidemia in the 20-29 years age group and the proportion of people with high total cholesterol / HDL was $54 \%$ overall. Study done by Sekhri et al (17) reported that there was a higher proportion of individuals with dyslipidemia with $45.6 \%$ of them having a high total cholesterol/HDL ratio. The proportion of people with obesity was $6.25 \%$ in the present study which is much lesser than a study conducted by Mannoci A et al (18) were obesity was found in $12.7 \%$.

Awareness and control of hypertension and diabetes was also poor, indicating low detection and poor management of major CVD risk factors. The high prevalence of such risk factors like impaired fasting glucose and pre hypertension suggests that there is a large vulnerable population which can develop an overt adverse risk profile and CVD in the future. The awareness and control seen in the study population is thus not convincing and is similar to data published from another study done in Industrial workers in Chennai, India (19).

In the past few decades many studies have shown that there is an increasing prevalence of CVD and its risk factors in India, as well as in many other South Asian countries (20).

The high prevalence of such risk factors like diabetes, impaired fasting glucose, and high blood pressure reflects the adaptation to westernized life style and urbanization in the Indian population and also the industrial employees. Even though a high prevalence of risk factors is a cause of concern, organized sector industries provide a unique opportunity for carrying out prevention programmes.

In India, there are atleast 2.8 crore people working in such organized sectors. (21) Most of the organized sector industries have their own health care facilities and also provide for healthcare of their employees and their dependents in higher medical centres if needed. With such increase in risk factors as is seen here, there will be for sure, an enormous burden on industries in terms of expenditure towards health care programmes.

The initiation of low-cost CVD prevention programmes at work place has been successful in the West which includes creating awareness through health education programmes and risk reduction interventions. Such programmes can also be tried in Indian settings which will give rise to a healthy workforce and will also increase the production in the industry.

This study thus provides a stimulus for initiating such surveillance and preventive activities. 


\section{Conclusion}

The prevalence of prehypertension and hypertension were $61.89 \%$ and $14.70 \%$ respectively. $14.6 \%$ had impaired fasting glucose and $5.9 \%$ were diabetic. The proportion of workers with hypercholesterolemia was $12.5 \%$, those with hypertriglyceridemia was $16.25 \%$ and workers who had high TC/HDL ratio was $54 \%$. $31.56 \%$ and $6.25 \%$ were preobese and obese respectively. $21.8 \%$ were current tobacco smokers. $61.56 \%$ had atleast one risk factor for coronary heart disease during the survey. This study demonstrates a high prevalence of risk factors and determinants for CVD. Despite the availability of a health care facility at the worksite itself, the workers knowledge of their hypertensive and diabetic status is low.

This study demonstrates a high prevalence of CVD risk factors, risk determinants such as obesity among a group of young industrial workers. Though the study population does not actually represent the general population, it reveals a rising trend of CVD in urban India. Despite the availability of a health care facility at the worksite itself, the workers knowledge of their hypertensive and diabetic status is low. Therefore, there is a pressing need to initiate onsite preventive programmes to identify and manage individuals at high risk of future CVD by optimal utilization of the available industrial physicians.

\section{Recommendation}

There is a pressing need to initiate onsite preventive programmes to identify and manage individuals at high risk of future CVD by optimal utilization of the available industrial physicians.

\section{Limitation of the study}

Since this study is done in industrial population, the results cannot be a representative of the general population. In the present study, there was a predominate male population and only $9.4 \%$ were females. The results cannot be generalized to people above 60 years also, in whom the risk factors and disease burden will be even higher than reported in the study population. Another limitation is that the workers were not subjected to ECG examination which could have been useful in identifying all those suffering from CHD and thus could have been excluded from the study. But this study was dependent on the patient's knowledge of their CHD/Stroke status.

\section{Relevance of the study}

While most people were aware of their diagnosis and were on treatment, there was a large gap between treatment and control. There is a lack of treatment intensification, which could possibly be a major determinant of the gap between treatment and control.

\section{Authors Contribution}

DPV: Conception and design of the work, Acquisition of data, Analysis and interpretation of data, Drafting the article; AGK: Conception and design, collecting references for the article, Revising the article critically; NKG: Acquisition of data, Data entry and analysis, Drafting a part of the article

\section{Acknowledgement}

We thank the management of the industry for giving us the permission to conduct this study. We thank the workers of the industry without whom this work would have never been possible.

\section{References}

1. WHO. Global status report on non-communicable diseases 2010, chapter 1. Geneva: World Health Organization;2011 http://www.who.int/nmh/publicatio ns/ncd report full en.pdf [ Last accessed on 2020 Dec 20]

2. Boutayeb A, Boutayeb $S$. The burden of noncommunicable diseases in developing countries. Int J Equity Health 2005;4:2

3. WHO.Non Communicable Diseases. Fact Sheet. http://www.who.int/mediacentre/factsheets/fs355/en L[ Last accessed on 2020 Dec 20]

4. Srinath Reddy K, Shah B, Varghese C, Ramadoss A. Responding to the threats of chronic diseases in India. Lancet 2005; 366:1744-9.

5. WHO. The world health report 2002. Geneva: World Health Organization; 2002. http://www.who.int/whr/2002/en/whr02_en.pdf. [ Last accessed on 2020 Dec 20]

6. World Health Organization. The Atlas of Heart Diseases and Stroke. Part Three: The Burden. Available at http://www.who.int/cardiovascular_diseases/en/cvd_a tlas 13 coronary HD.pdf[ Last accessed on 2020 Dec 20]

7. World Health Organization. The Atlas of Heart Diseases and Stroke. Part Three: The Burden. Available athttp://www.who.int/cardiovascular diseases/en/cvd atlas 14 deathHD.pdf[ Last accessed on 2020 Dec 20]

8. National Kidney Foundation guidelines. Measurement of Blood pressure in adults. Available athttp://www.kidney.org/professionals/kdoqi/guidelin es bp/guide 3.htm [ Last accessed on 2020 Dec 20]

9. Prabhakaran D, Shah P, Chaturvedi V, Ramakrishnan L, Manhapra A, Reddy KS.Cardiovascular risk factor prevalence among men in a large industry of 
northernIndia. Natl Med J India. 2005;18(2):59-65. PMID: 15981439.[PubMed].

10. Nigam PK. Serum Lipid Profile: Fasting or Non-fasting? Indian J Clin Biochem.2011;26(1):96-7. doi: 10.1007/s12291-010-0095-x. Epub 2010 Dec 29. PMID: 22211025; PMCID: PMC3068759.[PubMed].

11. Seventh report of the Joint National Committee on Prevention, Detection, Evaluation and Treatment of High Blood Pressure (JNC 7). Available at http://www.nhlbi.nih.gov/files/docs/guidelines/phycar d.pdf [ Last accessed on 2020 Dec 20]

12. American Diabetic Association. Diagnosis and classification of diabetes mellitus. Diabetes Care 2014;37(Suppl. 1):S81-S90.

13. "Third report of the National Cholesterol Education Program (NCEP) expert panel on detection, evaluation, and treatment of high blood cholesterol in adults (adult treatment panel III) final report", Circulation, 2002; 106: 3143-3421.

14. Grundy SM, Cleeman JI, Daniels SR, Donato KA, Eckel RH, Franklin BA, Gordon DJ, Krauss RM, Savage PJ, Smith SC Jr, Spertus JA, Costa F; American Heart Association; National Heart, Lung, and Blood Institute. Diagnosis and management of the metabolic syndrome: an American Heart Association/National Heart, Lung, and Blood Institute Scientific Statement. Circulation. 2005 25;112(17):2735-52.

doi: 10.1161/CIRCULATIONAHA.105.169404. Epub 2005 Sep 12. Erratum in: Circulation. 2005 Oct 25;112(17):e297. Erratum in: Circulation. 2005 Oct 25;112(17):e298. PMID: 16157765.[PubMed].
15. World Health Organisation. Obesity and overweight. Available

http://www.who.int/mediacentre/factsheets/fs311/en L[ Last accessed on 2020 Dec 20]

16. Pyakurel P, Karki P, Lamsal M, Ghimire A, Pokhare P K. Cardiovasular risk factors among industrial workers: a cross sectional study from Eastern Nepal. J Occup Med Toxicol 2016;11(25):1-7.

17. Sekhri T, Kanwar R S, Wilfred R, Chugh P, Chhillar M, Aggarwal $R$ et al. Prevalence of risk factors for coronary artery disease in an urban Indian population. BMJ Open 2014;4(12): e005346.

18. Mannocci A, Pignalosa S, Saulle R, Sernia S, De Sanctis S, Consentino M,Gialdi C, Nicosia V, La Torre G. Prevalence of major cardiovascular risk factorsamong oil and gas and energy company workers. Ann Ist Super Sanita.2015;51(2):148-53. doi: 10.4415/ANN_15_02_13. PMID: 26156186.[PubMed].

19. Kaur P, Rao T V, Sankarasubbaiyan S, Narayanan A M, Ezhil R, Ramachandra Rao $S$ et al. Prevalence and Distribution of Cardiovascular Risk Factors in An Urban Industrial Population in South India: A Cross-Sectional Study. J Assoc Physicians India 2007;55:771-6.

20. India State-Level Disease Burden Initiative CVD Collaborators. The changing atterns of cardiovascular diseases and their risk factors in the states ofIndia: the Global Burden of Disease Study 1990-2016. Lancet Glob Health. 2018;6(12):e1339-e1351. doi: 10.1016/S2214109X(18)30407-8. Epub 2018 Sep 12.PMID: 30219317; PMCID: PMC6227386. [PubMed].

21. Sathya P. Issues of unorganized labourers in India. Indian J Appl Res 2016;6(4):44-46.

\section{Tables}

\begin{tabular}{|l|l|l|l|}
\hline TABLE 1 AGE DISTRIBUTION OF THE STUDY POPULATION & \\
\hline Age group (years) & Male no. (\%) & Female no. (\%) & Total no. (\%) \\
\hline $20-29$ & $192(60)$ & $26(8.13)$ & $39(68.12)$ \\
\hline $30-39$ & $37(11.56)$ & $2(0.63)$ & $11(3.44)$ \\
\hline $40-49$ & $10(3.13)$ & $1(0.31)$ & $52(16.25)$ \\
\hline $50-59$ & $51(15.94)$ & $1(0.31)$ & $320(100)$ \\
\hline Total & $290(90.63)$ & $30(9.38)$ & \\
\hline
\end{tabular}

\section{TABLE 2 CLINICAL, LABORATORY AND ANTHROPOMETRIC MEASUREMENTS}

\begin{tabular}{|l|c|c|c|}
\hline Variable & Min value & Max value & Mean (s.d.) \\
\hline Age (years) & 20 & 59 & $31.63(11.04)$ \\
\hline Height (metres) & 1.47 & 1.87 & $1.68(0.07)$ \\
\hline Weight (kg) & 36 & 108 & $67.64(12.23)$ \\
\hline BMI (kg/m²) & 14.24 & 36.89 & $23.88(3.77)$ \\
\hline WHR (Waist Hip Ratio) & 0.78 & 0.92 & $0.84(0.07)$ \\
\hline SBP $(\mathrm{mmHg})$ & 90 & 180 & $120.33(13.44)$ \\
\hline DBP $(\mathrm{mmHg})$ & 60 & 100 & $77.67(8.44)$ \\
\hline FBS $(\mathrm{mg} / \mathrm{dl})$ & 70 & 336 & $95.55(24.25)$ \\
\hline Total Cholesterol $(\mathrm{mg} / \mathrm{dl})$ & 86 & 253 & $162.52(30.71)$ \\
\hline Triglycerides $(\mathrm{mg} / \mathrm{dl})$ & 18 & 291 & $101.48(51.92)$ \\
\hline LDL $(\mathrm{mg} / \mathrm{dl})$ & 47 & 181 & $107.45(26.62)$ \\
\hline HDL $(\mathrm{mg} / \mathrm{dl})$ & 20 & 93 & $35.99(8.50)$ \\
\hline
\end{tabular}




\begin{tabular}{|c|c|c|c|c|c|c|c|}
\hline Variables & Classifications & Cutoff point & $20-29$ & 30-39 & $40-49$ & 50-59 & Total (\%) \\
\hline & & & Yrs & Yrs & Yrs & Yrs & \\
\hline \multirow[t]{4}{*}{ BMI } & Underweight & $<18.50$ & 10 & 3 & 1 & 5 & $19(5.94)$ \\
\hline & Normal & $18.50-24.99$ & 114 & 27 & 8 & 31 & $180(56.25)$ \\
\hline & Preobesity & $25.00-29.99$ & 77 & 8 & 2 & 14 & $101(31.56)$ \\
\hline & Obesity & $\geq 30.00$ & 16 & 1 & 0 & 3 & $20(6.25)$ \\
\hline \multirow[t]{4}{*}{ SBP } & Optimal & $<120$ & 52 & 21 & 6 & 31 & 110 (34.38) \\
\hline & Pre Hypertension & $120-139$ & 145 & 16 & 3 & 15 & 179 (55.94) \\
\hline & Stage $1 \mathrm{HTN}$ & $140-159$ & 15 & 2 & 2 & 5 & $24(7.5)$ \\
\hline & Stage 2 HTN & $\geq 160$ & 4 & 0 & 0 & 3 & $7(2.19)$ \\
\hline \multirow[t]{4}{*}{ DBP } & Optimal & $<80$ & 59 & 19 & 5 & 31 & $114(35.63)$ \\
\hline & Pre HTN & $80-89$ & 130 & 15 & 4 & 14 & 163 (50.94) \\
\hline & Stage 1 HTN & $90-99$ & 23 & 3 & 1 & 4 & 31 (9.69) \\
\hline & Stage 2 HTN & $\geq 100$ & 4 & 2 & 1 & 5 & $12(3.75)$ \\
\hline \multirow[t]{3}{*}{ FBS } & Desirable & $<100$ & 157 & 37 & 10 & 50 & 254 (79.38) \\
\hline & Borderline & $100-125$ & 41 & 2 & 1 & 3 & 47 (14.69) \\
\hline & Increased & $\geq 126$ & 18 & 0 & 0 & 1 & $19(5.94)$ \\
\hline
\end{tabular}

TABLE 4 FREQUENCY DISTRIBUTION OF TOTAL CHOLESTEROL (TC), TRIGLYCERIDES (TGL), LOW DENSITY LIPOPROTEINS(LDL) AND HIGH-DENSITY LIPOPROTEINS (HDL)

\begin{tabular}{|c|c|c|c|c|c|c|c|}
\hline Variable & Classification & Cutoff points & $20-29$ & 30-39 & $40-49$ & $50-59$ & Total (\%) \\
\hline & & & Yrs & Yrs & Yrs & Yrs & \\
\hline \multirow[t]{3}{*}{ Total cholesterol } & Normal & $<200$ & 189 & 35 & 10 & 46 & $280(87.5)$ \\
\hline & Borderline & $200-239$ & 26 & 4 & 1 & 6 & 37 (11.56) \\
\hline & Increased & $\geq 240$ & 2 & 0 & 0 & 1 & $3(0.94)$ \\
\hline \multirow[t]{3}{*}{ Triglycerides } & Normal & $<150$ & 176 & 35 & 10 & 47 & $268(83.75)$ \\
\hline & Borderline & $150-199$ & 22 & 2 & 0 & 4 & $28(8.75)$ \\
\hline & Increased & $\geq 200$ & 19 & 2 & 1 & 2 & $24(7.5)$ \\
\hline \multirow{4}{*}{$\begin{array}{l}\text { Low density } \\
\text { Lipoproteins }\end{array}$} & Optimal & $<100$ & 82 & 19 & 3 & 22 & $126(39.38)$ \\
\hline & Desirable & $100-129$ & 90 & 15 & 7 & 17 & $129(40.31)$ \\
\hline & Borderline & $130-159$ & 38 & 5 & 1 & 10 & $54(16.88)$ \\
\hline & Increased & $\geq 160$ & 7 & 0 & 0 & 4 & $11(3.44)$ \\
\hline \multirow{2}{*}{$\begin{array}{l}\text { High density } \\
\text { Lipoproteins }\end{array}$} & Decreased & $<40$ & 156 & 21 & 11 & 37 & $225(70.31)$ \\
\hline & Desirable & $\geq 40$ & 61 & 18 & 0 & 16 & 95 (29.69) \\
\hline
\end{tabular}

